\title{
TINJAUAN HISTORIS LATAR BELAKANG DAN DAMPAK PERANG DENA TERHADAP KEHIDUPAN MASYARAKAT DENA KECAMATAN MADAPANGGA KABUPATEN BIMA TAHUN 1908-1910
}

\author{
Muaini ${ }^{1}$, Nurrafaah ${ }^{2}$, \\ ${ }^{1,2}$ Pendidikan Sejarah, Universitas Muhammadiyah Mataram, muaini.awir@gmail.com \\ ${ }^{2}$ Pendidikan Sejarah, Universitas Muhammadiyah Mataram
}

\section{INFO ARTIKEL \\ RiwayatArtikel:}

Diterima: 04-04-2017

Disetujui: 05-06-2017

\section{Kata Kunci:}

1. Tinjauan Historis

2. Perang Dena

\section{A. LATAR BELAKANG}

Praktik kolonialisme dan imperialisme yang dilakukan bangsa Belanda di Nusantara telah menimbulkan penderitaan bagi rakyat pribumi. Hal tersebut mengakibatkan berbagai bentuk perlawanan bersenjata yang dilakukan rakyat diberbagai daerah di Indonesia, salah satunya adalah perlawanan yang dilakukan oleh mayarakat Dena. Perang Dena disebut-sebut sebagai perlawanan rakyat besar di Sumbawa selama pemerintahan kolonial Belanda. Perang Dena berlangsung selama dua tahun yaitu antara tahun 1908-1910.

Pada zamannya, wilayah kekuasaan Kerajaan Bima khususnya Kesultanan Bima menjadi semakin

\section{ABSTRAK} Dena Tahun 1908-1910, serta Menganalisis Dampak Positif Perang Dena Terhadap an Masyarakat Dena Tahun 1908-1910. besar yang pernah diami oleh masyarakat Dena dalam menghadapi penjajahan Belanda. (2). Proses terjadinya Perang Dena tahun 1908-1910, Manyarakat Dena merupakan salah satu daerah yang menentang kolonial Belanda karena telah melihat (3).Akibat peperangan masyarakat dena mengalami kerugian besar baik moril, Meterial dan mengakibatkan korban jiwa yang tidak sedikit. 1908-1910 and Describe the Dena War of 1908-1910, and Analyze the Positive Impact of Dena

The research method used is qualitative method. Data obtained based on obsevation, interviews and documentation. The conclusions of this research are: (1). The background of the (2). The process of the Dena War in 1908-1910, Manyarakat Dena is one of the areas opposing the Dutch colonial because it has seen the various oppression they do to the people. (3) .The result of community wars dena suffered huge losses both morale, Meterial and resulted in casualties are not small.

sempit karena banyak daerah yang di ambil alih oleh pemerintah kolonial Belanda. Di lingkungan istana Bima sendiri terdapat dua golongan, satu golongan berpihak kepada pemerintah kolonial Belanda, sementara pihak lain menentang pemerintah Belanda. Manyarakat Dena merupakan salah satu daerah yang menentang kolonial Belanda karena telah melihat berbagai penindasan yang mereka lakukan kepada rakyat. Perjuangan masyarakat Dena dibantu oleh H. Usman yang juga menjadi pemimpin spiritual pemberontakan. Dalam perang Dena ini telah berjatuhan korban yang tidak sedikit.

Baik korban harta maupun jiwa. Dokumendokumen Belanda yang dikutip para ahli sejarah, 
disebutkan bahwa sekitar 100 jiwa rakyat yang terenggut. Sementara itu di pihak serdadu Belanda, korban tewas berjumlah 50 jiwa. Perang Dena merupakan salah satu pertempuran besar yang pernah dialami oleh Belanda selama menjajah Nusantara. Peperangan ini melibatkan seluruh wilayah Bima, maka disebutlah Perang ini sebagai Perang Bima. Karena masyarakat Dena tidak ingin wilayahnya dijajah oleh Belanda karena mereka menganggap Belanda ingin menguasai masyarak tersebut sehinggan bertentangan dengan datangnya Belanda karena mereka menganggap Belanda ingin menguasai daerah Dena sehingga mereka tidak ingin daerahnya didatangi oleh Belanda atau dengan sebutan orang kafir. Masyarakat Dena sejak dahulu telah dikenal adalah masyarakat yang religius. semua pelaksanaan dari suatu kegiatan dilandasi dengan suatu aturan yang bertalian dengan agama Islam yang dianutnya.

Desa Dena merupakan desa diantara 16 desa di wilayah Kecamatan Madapangga daerah Kabupaten Bima Propinsi Nusa Tenggara Barat. Saat ini telah mencapai tinggal Desa Swasembada. Status ini telah dicapai berkat adanya ketekunan penduduk yang kian tahun menunjukan kesadaran dan partisipasi aktif dalam segala bentuk kegiatan pembangunan terutama dibidang pertanian. Desa Dena beriklim sama dengan iklim daerah lain sama dengan iklim daerah Kabupaten Bima pada umumnya. Curah hujan paling kurang jika dibandingkan dengan curah hujan di Indonesia pada umumnya.

Dalam sejarahnya, pada awal abad ke 16 Belanda telah mulai menginjakan kakinya di daerah Bima. Saat itu daerah Bima kaya dengan hasil pertanian dan hasil hutannya. Pada awalnya Belanda membawa misi perdagangan disamping sebagai misi agama Nasrani. Mula pertama kedatangan Belandadi Bima meminta ijin kepada Sri Sultan Bima untuk mendirikan markasnya di Lawe Duwe dekat kampung benteng sekarang ini. Markas tersebur adalah markas perdagangan, tetapi pada hakekatnya adalah sebuah benteng tempat tersebut sangat strategis sekali karena sebagai tempat masuknya kapal dari daerah luar. Pintu masuk tersebut merupakan pintu atau asa kota. Kedatangan Belanda membuat resah masyarakat Bima, orang Dena sendiri tidak ingin agama Islam yang dianutnya bercampur aduk dengan agama lainnya apalagi yang namanya kafir. Pembaruan dengan agama lain sangat dibencinya.

Pada tahun 1908 kerajaan Bima dalam keadaan goncang, suasana politik dalam negeri Kesultanan Bima dalam keadaan hangat. Dilain dari itu, kekhawatiran ini bertambah menjadi, ketika utusan pemuka Ngali atas perintah Ompu Kapa'a membawa berita bahwa desa Dena dan desa Ngali akan diserang oleh Belanda. Karena itu mereka bersiap setiap waktu. Untuk itu Ompu Dena dan segenap alim ulama mengadakan musyawarah di Masjid Dena, terus semua alim ulama dikumpulkan untuk bermusyawarah dan sekaligus meminta pertolongan agar diberikan kekuatan sebelum peperangan terjadi.Dengan alasan ini peneliti melakukan penelitian untuk mengungkapkan dan menjelaskan peristiwa yang berlangsung pada masa silam dengan fakta sesuai kerja historisnya.

Dari beberapa penjalasan diatas, peneliti tertarik melakukan penelitian yang mendalam tentang "tijauan historis latar belakang dan dampak perang Dena terhadap kehidupan masyarakat Dena Kecamatan Madapangga Kabupaten Bima tahun 1908-1910”. Hal ini dilakukan peneliti karna peneliti sendiri berasal dari desa Dena, selain dari itu peneliti tertarik untuk memperkenalkan kepada masyarakat Indonesia pada umumnya dan masyarakat Bima pada khususnya bahwa masyarakat Dena pernah pelakukan perlawan terhadap kolonialisme Belanda pada tahun 1908-1910, inilah cikal bakal timbulnya keberanian dan nasionalisme masyarakat Bima melawan para kolonialisme yang telah mencoba mengabur radukan tatanan kehidupan masyarakat Bima baik material maupun jiwa dan raga.

\section{B. METODE PENELITIAN}

Penelitian mengenai "Tinjauan Historis Latar belakang dan Dampak Perang Dena Terhadap Kehidupan Masyarakat Dena Tahun 19081910"merupakan suatu penelitian historis dengan pendekatan kualitatif deskripsikan karena penelitian ini diarahkan untuk meneliti, mengungkapkan dan menjelaskan peristiwa masa lampau sehingga jelas 
diarahkan kepada pendekatan Historis. Metode kualitatif adalah metode penelitian yang berlandaskan pada filsafat postpositivisme, digunakan untuk meneliti pada kondisi obyek yang alamiah (Sugiyono,2010:15). Tujuan dari penilitian Historis ini yaitu menemukan dan mendeskripsikan secara analisis tentang sejarah perang Dena. Selain itu penelitian yang saya lakukan terkait dengan “Tinjauan Historis Latar Belakang dan Dampak Perang Dena Terhadap Kehidupan Masyarakat Dena". Tehnik pengumpulan data menggunakan observasi, wawancara dan dokumentasi.

\section{HASIL DAN PEMBAHASAN}

\section{Latar Belakang Terjadinya Perang Dena Tahun 1908-1910}

Pada awalnya kedatangan Bangsa Belanda

diterima dengan baik oleh Masyarakat Bima terutama oleh Masyarakat Dena karena mereka menganggap kedatangan Bangsa Belanda akan membantu Masyarakat dalam membangun Masyarakat menjadi lebih baik terutama dalam segi pendidikanya. Namun pada kenyataannya kedatangan Bangsa Belanda hanya menimbulkan kebencian di hati Masyarakat. Masyarakat, pada situasi yang sangat merugikan Bangsa Belanda ingin merampas kekayaan dan wilayah Desa Dena.

Mereka melawan karena tidak mau menerima bea pajak, kerja paksa dan tunduk di bawah perintah orang kafir. Rakyat Dena mempersiapkan diri menghadapi segala kemungkinan yang mungkin terjadi sebagai resiko dari sikap tersebut. Di sekeliling kampung dibuatkan benteng pertahanan mempersiapkan tempat berlindung bagi perempuan, anak-anak beserta orang tua berusia lanjut bila saatnya "Bala" menimpa kampung. Para ulama membakar semangat juang rakyat dengan fatwa yang menggemakan perang sabi. Sultan Ibrahim menghadapi percobaan berat untuk kedua kalinya dalam waktu yang bersamaan. Sultan tidak mampu untuk menghadapi dan menyerahkan penyelesaian sepenuhnya kepada pemerintah Hindia Belanda. Residen Belanda di Makassar mengirimkan ekspedisi militer dengan mempergunakan dua buah kapal dengan kekuatan seribu personil serdadu di bawah pimpinan Overste G. T. King. Tiba di Bima pada tanggal 2 April 1910.
Beberapa hari kemudian serdadu Marsose Belanda menyerang Desa Dena. Dalam perjalanan kesana pasukan Belanda di hadang dan di sergap oleh lasykar Dena yang bersenjatakan keris, tombak dan beberapa pucuk bedil. La Lede Ama Ibu laskar rakyat pertama yang melepaskan tembakan dan meminta korban seorang serdadu marsose. Serangan dadakan ini tidak di sangka pihak musuh sehingga pasukan Belanda menjadi kacau balau. Sasaran utama Belanda sebenarnya menuju gunung Lebe dan dari sana menyerang Desa Dena.

Kekuatan yang seimbang serta persenjataan yang memiliki kualitas dan kuantitas sehingga laskar rakyat mengambil posisi bertahan. Laskar di bawah pimpinan $\mathrm{H}$. Usman Abu Beda bertahan di tolo Sera, pertempuran seruh terjadi disana dalam kampung yang sedang terbakar. Lasykar H. Usman bertahan dalam rumah penduduk dan terjadi perkelahian yang sangat hebat. Pasukan Belanda berusaha untuk menyergap pemimpin perlawanan H. Abdul Ajis Abu Saleh. Dengan menggunakan anggota laskar yang tertawan H. Hamu sebagai petunjuk jalan ke markas perlawanan rakyat di Karama Bura. Markas di kawal oleh Ompu Aco seorang yang terkenal kebal peluru. Menghadapi kepungan Belanda Ompu Aco tidak melawan melainkan minta ampun demi keselamatan perempuan dan anak-anak yang berlindung dalam markas itu. Sikap Ompu Aco di sambut dengan menembak Ompu Aco. Karena Ompu Aco kebal peluru hal mana membuatkan serdadu Marsose menjadi bringas. Markas itu di bakar dan di tembaki, semua orang yang berada dalam markas terbunuh termasuk Ompu Aco.

Haji Abdul Azis dengan sejumlah lasykar berhasil meloloskan diri dari kepungan Belanda. Tembakmenembak terjadi di sekitar markas, Haji Abdul Azis, Haji Mustafa Abu Hawa dan Muhammad Ama Zena tertangkap. Dengan tertangkapnya mereka maka praktis berakhir perlawanan rakyat Dena. Para pemimpin rakyat yang tertangkap dipaksakan untuk menandatangani perjanjian yang berisi : a). Rakyat Dena harus mengakui kekuasaan Belanda dan berjanji tidak akan melakukan perlawanan lagi. b). Sebagai ganti rugi perang mereka harus membayar seratus ringgit (a ringgit $=\mathrm{f} 2,50,-)$. 
Cukup banyak serdadu Marsose terbunuh atau sakit dalam perang ini. Menurut pengakuan Overste G.T. King sendiri banyak serdadunya yang hilang karena keganasan alam hutan belukar, rawa-rawa dan penyakit malaria. Pasukan Belanda kembali kepangkalan di kampung benteng. Beberapa hari kemudian diangkut kembali ke Makassar. G.P. Rouffaer dalam perjalanan menuju Palama-Donggo singga di Sila pada bulan Agustus 1910, mengatakan bahwa ia merasa senang karena Sila pada waktu itu di persenjatai dan dijaga ketat. Keadaan Masyarakat tenang dan tenteram. Pernyataan tersebut memberikan petunjuk bahwa kehidupan Masyarakat berjalan normal seusai perang Dena dan perang Rasa Nggaro yang dipimpin la Seo, la Usu, Dae Sumbu dan lain-lain, namun penanggung jawab keamanan tetap dalam siaga, guna segera menangkal kemungkinan-kemungkinan lain yang akan timbul mengirimkan utusan ke Dena, utusan itu dipimpin oleh Badula Uba Unu, guna menjumpai gelarang Dena ( Sebutan bagi kepala desa ). Saat itu gelarang Dena dipegang oleh La Kao Ama Huse, utusan itu membawa berita bahwa Ompu Dena dengan segenap penduduknya beserta para alim ulamanya harus mengakui dan tunduk pada hasil musyawarah di Pena Pali.

Selanjutnya pesan itu mempertegas agar, bila Belanda jangan dilawan, karena kalau dilawan akan menimbulkan masalah yang tidak dikehendaki. Menerima kedatangan orang Belanda bukan berarti kita tunduk kepada Belanda. Kebijaksanaan ini merupakan cara diplomasi dari Sri Sultan Bima untuk menjaga terjadinya hal-hal yang tidak dikehendaki berhubung pada saat itu suasana kerajaan Bima dalam keadaan tidak normal. Pesan Sri Sultan ini belum bisa diterima Ompu Dena karena beberapa tuan guru Dena tidak berada di tempat (H. Usman Abu Jenggo dan H. Abdul Aziz sedang berada di Ngali) dalam rangka pertukaran tuan guru.

Kembalilah utusan itu ke Bima dengan tidak membawa hasil. Sekembalinya Tuan Guru H. Usman dari Ngali, maka diundanglah segenap Tuan Guru dan para ulama yang ada di desa, diadakanlah musyawarah dengan mengambil tempat di Masjid Dena. Ompu Dena menyampaikan pesan Sri Sultan Bima yang diterimanya lewat utusan sebagai berikut: a). Masyarakat Dena harus mengakui membayar belasting terhadap Belanda, b). Masyarakat Dena harus menerima kedatangan orang Belanda di Dena dengan Masyarakat tidak usah dilawan. Setelah diadakan rembuk bersama dibulatkanlah tekad dan menetapkan: 1). Membayar belasting pada Belanda berarti takluk pada Belanda, 2). Takut kepada Belanda berarti telah dijajah oleh Belanda dan akan menodai kemurnian agama Islam yang dianut oleh Masyarakat, di jajah oleh Belanda berarti kafir. Dari pada kafir lebih baik melaksanakan perang sabil karena perang sabil itu adalah peunjuk agama.

Karena pesan dari Sultan Bima tidak mendapat tanggapan baik dari Masyarakat Dena, maka Sri Sultan mengirimkan utusan yang kedua kalinya di pimpin oleh Pajuri Jala. Pesan raja, jika Masyarakat tidak mau mengerti maka akan terjadi peperangan. Sri Sultan Bima tidak mau bertanggung jawab terhadap peristiwa yang akan terjadi. Maksud kunjungan itupun mengalami kegagalan, beberapa pemuka agama belum kembali di tempat, malah beberapa ulama lainnya berpergian ada yang ke Ngali, Dodu, dan malah ada yang ke Daerah kerajaan Dompu. Tuan Guru tersebar ke luar kampung karena beberapa hari lagi akan tiba bulan puasa ramadhan. Kecurigaan Sri Sultan Bima semakin menjadi. Masyarakat dan alim ulama Dena masih berpegang pada prinsipnya waktu musyawarah di Pali Pena.

Pada bulan Maret 1910 Sri Sultan mengirimkan utusannya yang ketiga kalinya di pimpin oleh Rato Parenta dan di dampingi oleh dua orang pengawal. Sesampainya di Sila utusan tersebut mengajak tuan guru dari Sila yang bernama H. Mahamu. Rato parenta tau betul bahwa Tuan Guru H. Mahamu mempunyai hubungan keluarga dengan tuan guru Dena. saat iu putra Tuan Guru H. Mahamu ingin dipertunangkan dengan putri tuan guru H. Abdurrahim alias Abu To"i yang bernama St. Rukaya. dengan kehadiran H. Mahamu di Dena akan diharapkan melicinkan jalan untuk memahami isi harapan Sri Sultan Bima. Utusan itu diterima oleh Ompu Dena dengan segenap alim ulama yang dipimpin oleh H. Usman (Abu Jenggo) seusai utusan itu menyampaikan utusan Sri Sultan Bima, H. Usman alias Abu Jenggo memberikan harapan juga: "Wahai rato parenta utusan paduka Sri Sultan Bima, ambun beribu 
ampun hamba atas nama sekalian teman dan Masyarakat seisi kampung kami hantarkan kehadapan paduka raja Sri Sultan Ibrahim yang merajai sejagat raya di antero paju Mbojo. sujud hamba mulai dari telapak kaki sampai keujung rambut.

Titah Baginda Sri Sultan semuannya kami junjung tinggi, beratnya kami pikul bersama, dan ringannya jangan dikata. Titah Baginda Sri Sultan kali ini oleh hamba dan sekalian penduduk Dena yang tiada berdaya ini dirasa sangat berat. Orang Belanda menginjakkan kakinya di Dena berarti telah menodai agama Islam yang telah dianut oleh segenap penduduka desa Dena pada khususnya dan Masyarakat dou Mbojo pada umumnya. Orang Belanda adalah orang kafir karena itu kami mohon agar orang Belanda dilarang masuk dan menginjakkan kakinya di Desa Hamba, kalau Belanda diijinkan masuk berarti Belanda telah menginjak dan menodai Masyarakat tanah Mbojo yang tercinta ini. Masyarakat Dena ingin menyucikan Agama Islam yang dianut oleh seantero manusia yang

\section{Prosesi Perang Dena}

Masyarakat Dena tidak ingin agama islam yang dianutnya bercampur aduk dengan agama lainnya apalagi yang namanya kafir. Pembaruan dengan agama lain sangat dibencinya. Pada tahun 1908 Kerajaan Bima dalam keadaan gonjang. Suasana politik dalam negeri Kesultanan Bima dalam keadaan hangat, saat itu Sri Sultan Bima mengirimkan utusan ke Dena, utusan itu dipimpin oleh Badula Uba Unu, guna menjumpai gelarang Dena ( Sebutan bagi kepala desa ). Saat itu gelarang Dena dipegang oleh La Kao Ama Huse, utusan itu membawa berita bahwa Ompu Dena dengan segenap penduduknya beserta para alim ulamanya harus mengakui dan tunduk pada hasil musyawarah di Pena Pali. Selanjutnya pesan itu mempertegas agar, bila Belanda jangan dilawan, karena kalau dilawan akan menimbulkan masalah yang tidak dikehendaki. Menerima kedatangan orang Belanda bukan berarti kita tunduk kepada Belanda. Kebijaksanaan ini merupakan cara diplomasi dari Sri Sultan Bima untuk menjaga terjadinya hal-hal yang tidak dikehendaki berhubung pada saat itu suasana kerajaan Bima dalam keadaan tidak normal. Pesan Sri Sultan ini belum bisa diterima Ompu Dena karena beberapa tuan guru Dena tidak berada di tempat (H. Usman Abu Jenggo dan H. Abdul Aziz sedang berada di Ngali) dalam rangka pertukaran tuan guru.

Kembalilah utusan itu ke Bima dengan tidak membawa hasil. Sekembalinya Tuan Guru H. Usman dari Ngali, maka diundanglah segenap Tuan Guru dan para ulama yang ada di desa, diadakanlah musyawarah dengan mengambil tempat di Masjid Dena. Ompu Dena menyampaikan pesan Sri Sultan Bima yang diterimanya lewat utusan sebagai berikut: a). Masyarakat Dena harus mengakui membayar belasting terhadap Belanda, b). Masyarakat Dena harus menerima kedatangan orang Belanda di Dena dengan Masyarakat tidak usah dilawan. Setelah diadakan rembuk bersama dibulatkanlah tekad dan menetapkan: 1). Membayar belasting pada Belanda berarti takluk pada Belanda, 2). Takut kepada Belanda berarti telah dijajah oleh Belanda dan akan menodai kemurnian agama Islam yang dianut oleh Masyarakat, di jajah oleh Belanda berarti kafir. Dari pada kafir lebih baik melaksanakan perang sabil karena perang sabil itu adalah peunjuk agama.

Karena pesan dari Sultan Bima tidak mendapat tanggapan baik dari Masyarakat Dena, maka Sri Sultan mengirimkan utusan yang kedua kalinya di pimpin oleh Pajuri Jala. Pesan raja, jika Masyarakat tidak mau mengerti maka akan terjadi peperangan. Sri Sultan Bima tidak mau bertanggung jawab terhadap peristiwa yang akan terjadi. Maksud kunjungan itupun mengalami kegagalan, beberapa pemuka agama belum kembali di tempat, malah beberapa ulama lainnya berpergian ada yang ke Ngali, Dodu, dan malah ada yang ke Daerah kerajaan Dompu. Tuan Guru tersebar ke luar kampung karena beberapa hari lagi akan tiba bulan puasa ramadhan. Kecurigaan Sri Sultan Bima semakin menjadi. Masyarakat dan alim ulama Dena masih berpegang pada prinsipnya waktu musyawarah di Pali Pena.

Pada bulan Maret 1910 Sri Sultan mengirimkan utusannya yang ketiga kalinya di pimpin oleh Rato Parenta dan di dampingi oleh dua orang pengawal. Sesampainya di Sila utusan tersebut mengajak tuan guru dari Sila yang bernama H. Mahamu. Rato parenta tau betul bahwa Tuan Guru H. Mahamu mempunyai hubungan keluarga dengan tuan guru Dena. saat iu 
putra Tuan Guru H. Mahamu ingin dipertunangkan dengan putri tuan guru H. Abdurrahim alias Abu To"i yang bernama St. Rukaya. dengan kehadiran H. Mahamu di Dena akan diharapkan melicinkan jalan untuk memahami isi harapan Sri Sultan Bima. Utusan itu diterima oleh Ompu Dena dengan segenap alim ulama yang dipimpin oleh H. Usman (Abu Jenggo) seusai utusan itu menyampaikan utusan Sri Sultan Bima, H. Usman alias Abu Jenggo memberikan harapan juga: "Wahai rato parenta utusan paduka Sri Sultan Bima, ambun beribu ampun hamba atas nama sekalian teman dan Masyarakat seisi kampung kami hantarkan kehadapan paduka raja Sri Sultan Ibrahim yang merajai sejagat raya di antero paju Mbojo. sujud hamba mulai dari telapak kaki sampai keujung rambut.

Titah Baginda Sri Sultan semuannya kami junjung tinggi, beratnya kami pikul bersama, dan ringannya jangan dikata. Titah Baginda Sri Sultan kali ini oleh hamba dan sekalian penduduk Dena yang tiada berdaya ini dirasa sangat berat. Orang Belanda menginjakkan kakinya di Dena berarti telah menodai agama Islam yang telah dianut oleh segenap penduduka desa Dena pada khususnya dan Masyarakat dou Mbojo pada umumnya. Orang Belanda adalah orang kafir karena itu kami mohon agar orang Belanda dilarang masuk dan menginjakkan kakinya di Desa Hamba, kalau Belanda diijinkan masuk berarti Belanda telah menginjak dan menodai Masyarakat tanah Mbojo yang tercinta ini. Masyarakat Dena ingin menyucikan Agama Islam yang dianut oleh seantero manusia yang berada di Desa Dena. apalah artinya, jika Belanda menginjakan kakinya di Desa Dena. Karena itu perkenankan permohonan hamba atas segenap penduduk, agar niat baik dari Sri Sultan dapat dipikirkan lebih matang lagi kalaupun Belanda terpaksa masuk di negeri hamba, maka dengan segala kemampuan yang ada pada diri hamba dan segenap penduduk akan mencoba mempertaruhkan nyawa. Masyarakat Dena akan melawan dengan semboyan perang sabil yang kedua hamba berharap agar belasting dan punguan berupa apa saja janganlah dipungut oleh Belanda, tetapi sudilah pungutan itu ditangani langsung oleh Raja”.

Sekembalinya utusan Sri Sultan Bima, pemuka Masyarakat dan alim ulama merasa tidak aman. Setiap saat selalu saja dibayangi oleh perasaan dan bayangan yang tidak menentu. Hal tersebut disebabkan karena apa yang diharapkan oleh Sri Sultan Bima lewat utusannya Rato Parenta di tolak. Dalam perkiraan pasti Belanda akan datang dengan cara paksa untuk melaksanakan maksudnya. Untuk itu Ompu Dena dan segenap alim ulamanya mengadakan musyawarah di masjid Dena. Semua alim ulama dikumpulkan, semua orang kebal dan tahan makan besi dipanggil. Keputusan musyawarah menetapkan : a), kedatangan Belanda di Dena harus dilawan dengan perang sabil, b) Senjata yang dipakai adalah bedil tumbuk, keris, parang, golok dan tombak, c). Tugas sebagai pemimpin di setiap medan ditetapkan sbb:

1) Panglima perang ditetapkan adalah $\mathrm{H}$. Usman (Abu Jenggo), 2) Pembanu-pembantunya adalah H. Abdul Aziz, H. Aburrahim, La Mahamu Ama Beda, Ompu Anco, H. Hasan, H. Abubakar, H. Husen dan H. Mustafa. 3) Markas perang ditetapkan di masjid Dena. 4) Dalam peperangan harus menggunakan azimat yang dituliskan pada sebuah perisai yang terbuat dari kulit kerbau. di samping perisai, setiap orang yang berperang harus meneriakkan Allahuakbar. 5) Membuat benteng keliling Desa di sebelah Timur dari Sori Ngonco sampai di Wadu Kandinci, melawati Wadu Karia Hoe,6). Pengungsian penduduk keluar Desa, 7). Perlawanan dilakukan diluar Desa, 8). membuat ranjau dari bambu /raba sebagai pagar rumah penduduk.

Di Sori Ngonco dan Sori Lebo telah ditunggu oleh pasukan Dena di bawah pimpinan Lede Ama Ibu dan La Sini Ama Tima. Pasukannya berjumlah 10 orang, sejak pagi ditunggu, baru pada jam 14.00 terliha iringan serdadu Belanda dari arah timur, karena melihat pasukan Belanda banyak pasukan Dena terpaksa mundur ke Sori Ngonco di sana terjadi peperangan. pasukan dena mencoba memulai tembakan dengan senapan tumbuk yang dimilikinya. Tombak dan keris sudah mulai difungsikan. saat itu tiba-tiba datang banjir besar di Sori $L e ' b o$. pertempuran hanya berlangsung beberapa saat saja. Pasukan Dena mengundurkan diri ke seberang sungai, sedangkan pasukan Belanda tetap berada di Sori Ngonco. Pasukan Dena langsung menuju karia hoe untuk bergabung dengan pasukan la Muhama Ama Beda. 
Pada sore hari sekitar jam 16.00 sore, Pasukan Belanda tiba-tiba muncul melewati Tolo Bou, mereka kewalahan karena tidak menemukan jalan masuk desa. Pada saat mereka mencari jalan masuk ke Desa itulah pasukan sambil mencoba melepaskan tembakan beberapa kali. Keadaan itu menembah panas bagi serdadu Belanda. Kemarahan Belanda memuncak. Benteng itu dibakarnya habis-habis sehingga dengan mudah tentara Belanda masuk di Wadu Karia Hoe telah ditunggu oleh gabungan pasukan sabil. Tolo Sera pada saat itu telah di tanami padi. Tanahnya becek berlumpur terjadi pertempuran sengit ditempat itu suara bedil dan gema Allahuakbar menggemuruh, namun pasukan sabil tidak gentar karena mereka sudah menganggap dirinya telah dipersenjatai dengan ilmu kebal dan tahan makan besi, pasukan sabil maju terus dengan maksud untuk melawan dari dekat.

Tentara Belanda mengalami kesulitan karena pada tempat pertempuran itu penuh dengan tanah lumpur dan rawa air sehingga sulit untuk bergerak dengan cepat. Kesempatan baik buat pasukan sabil untuk memainkan peranan dengan ilmu kebal yang mereka miliki. sementara la Sini Ama Tima dan La Lede Ama Ibu terpaksa harus mengakui keunggulan tentara Belanda. pada saat itu pula La Sini Ama Tima dan La Lede Ama Ibu tewas kena peluru tepat kena dadanya, sedangkan Ompu Barahi dan beberapa temannya ditawan Belanda. karena hari sudah mulai malam, pertempuranpun terhenti. Tentara Belanda membuat kemah dilapangan disekitar Tolo Sera yaitu di Fo'o Fanggi, mereka membuat kemah di bawah pepohonan dan disitulah sempat Belanda mengetahui segala taktik siasat pasukan sabil dari tawanan mereka yaitu Ompu Barahi dan kawan-kawannya.

Pada malam hari itu tentera Belanda mendapat serangan tentara Allah yaitu gigitan nyamuk, kebetulan di tempat itu terdapat sebuah tempat rawa yaitu So Mbanggu adalah tempat serangan nyamuk malaria yang sebelum itu adalah pusat nyamuk malaria yang selalu menghantui Masyarakat Dena. Dari peperangan di Tolo Sera itu telah gugur beberapa orang pasukan sabil, disamping Lede Ama Ibu dan Sini Ama Tima, namun dari pihak Belanda juga telah menjadi korban seorang pembantu pimpinan perangnya bernama Marsose di samping sejumlah besar orang serdadu Belanda lainnya.

Karena Sini Ama Tima dan Lede Ama Ibu telah tewas dalam pertempuran di Tolo Sera, maka kekuatan seakan-akan mengendor. dimana keduanya adalah orang yang dapat mempertahankan perlawanan dari musuh. keduanya adalah termasuk orang yang kebal, ditambah lagi beberapa anggotanya ditawan oleh Belanda tentu saja strategi dan segala rahasia perjuangan sudah diketahui oleh Belanda, pada malam harinya pejuang Belanda mengubah strategi. Kini perjuangan dipusatkan di lokasi Desa Dena dengan cara masuk dan bersembunyi dalam kolong lewat di samping rumah, maka segera ikatan pagar rumah yang dibuat dari bambu itu segera dilepaskan dan terus diinjak-injak. Pasukan yang berada di Wadu Bura dan di Mangge Kopa segera disatukan untuk memperkuat pertahanan yang ada dalam desa dan memperkuat markas di Masjid Raya Dena yang dipimpin oleh Abu Jenggo, H. Musafa dan H. Abdul Aziz.

Pada waktu pagi harinya Belanda mulai menyerang dari arah Timur mulai memasuki Desa menyebar mencari markas yang telah ditentukan. Mereka tidak mempunyai perhatian pada Masyarakat yang ada di dalam Desa karena mereka tahu bahwa pimpinan peperangan telah mempertahankan markas sabil yang berada di Wadu Bura dan Mangge Kopa. Namun yang mereka jumpai disana hanyala hening dan sepi, akhirnya mereka mulai memasuki desa dan tersebar disegala penjuru. Dicarilah pusat markas yang berada di masjid Raya Dena, di dalam perjalanan menuju masjid, terdengarlah teriakan Allahu Akbar yang menggema di udara bersahut-sahutan. suara teriakan Allahu Akbar ini seraya berasal dari orang tua-tua yang dikumpulkan pada sebuah rumah panggung yang merupakan milik dari $\mathrm{H}$. Abdurrahim Alias Abu To"i (Abu La Sara ) dan pada saat itu Abdurrahim bertindak sebagai penjaga musuh dihalamannya. Dihalaman rumahnya duplikat bendera perang Dena yang bertuliskan. "Laailahaillallah Muhammadarrasulullah".

Setelah pasukan Belanda melihat keadaan semacam itu dilepaskanlah tembakan oleh Belanda. $\mathrm{H}$. Abdurrahim belum sempat melepaskan tombak dan keris 
pusaka yang ada ditangannya, sedangkan peluru Belanda telah lebih dahulu menembus dadanya. Pada saat itu juga beliau menghembuskan nafasnya yang terakhir. Tembakan peluru Belanda semakin mengganas menuju ke arah rumah panggung berdinding papan milik $\mathrm{H}$. Abdurrahim. Ucapan Allahuakbar tetap menggema diudara, peluru yang bertubi-tubi ditembakan itu satu persatu mengenai sasarannya. Manusia seisi rumah yang berjumlah lebih kurang 20 orang, dan tertinggal sisa 2 orang yang masih hidup. Mereka itu ialah La Tija Ina Biba dan La Jena, keduanya kena peluru pada pahanya. Akhirnya mereka cacat dan kakinya pincang, sehingga dimasa hidupnya kedua pahlawan itu dijuluki dengan Wa'i Biba Ncepa dan Wa'i Janu bari. Sumber cerita diperoleh dari Wa'i Biba Ncepa dan Wa'i Janu Bari. Para suhada ini semuanya dimakamkan dalam satu liang lahat yang berlokasi di halaman muka masjid Raya Baitus Syuhada Dena sekarang ini, kini kuburan tersebut telah kabur, sebahagiannya telah dipindahkan ke lokasi lain kira-kira pada tahun 1966.

Pada malam harinya telah dialihkan ke rumah $\mathrm{H}$. Abdurrahim. Mereka mengintip di kolong rumah sambil menunggu pasukan Belanda datang, bila pasukan Belanda mendekati rumah itu, langsung mereka melepaskan pagar rumah (Raba). pagar rumah yang terbuat dari bamboo itu ditindiskan pada tubuh musuh selanjutnya kerisnya ditempat itu seorang serdadu Belanda tewas. Mayatnya dikuburkan di ujung Timur laut Desa Dena. kini biasa disebut orang tempat itu dengan sebuan Rade Bari (Kubur Belanda). Tempat itu adalah sebuah kubangan kerbau rakyat, sekarang lokasi tersebut telah dijadikan tempat perumahan rakyat.

Tiga orang pimpinan di markas yaitu di masjid Dena yang letaknya 100 meter dari sebelah Barat Masjid Raya Dena bersisian dengan tepi sungai Dena. Ketika Belanda menyerang markas penghuninya tidak ada di tempat. Perlawanan terhadap Belanda terhenti. Bendera perang yang terpasang di halaman masjid direbut Belanda dan langsung dibakarnya. beberapa orang tawanan termasuk Ompu Anco dan pembesar Belanda melanjukan perjalanan menuju sebuah tempat bernama Wadu Bura. Dua ratus meter jauhnya dari masjid Dena yang menjadi markas perang terdapat sebuah tempat bernama Wadu Bura. Tempat itu merupakan bagian dari sebuah kampung zaman silam yang dijuluki sekarang dengan nama Rasa Ntor. Ditempat itu bermukim keluarga besar Ompu Anco, oleh Ompu Anco memberi petunjuk kepada Belanda untuk pergi ke Wadu Bura. Diperkirakan tiga orang pimpinan perang Dena telah mengungsikan dirinya ke desa. Ternyata mereka telah berpindah tempat. Oleh mereka tempat itu juga dijadikan tempat bermusyawarah sebelum perang terjadi.

Atas prakarsa Mahamu Ama Beda ketika pimpinan itu dipanggil untuk hadir di wadu bura termasuk La Kao Ama Huse. Ditempat itu dibuatkan semacam perjanjian dan pernyataan yang isinya antara lain: a). Pimpinan perang dena harus segera menghadap Sri Sultan Bima, b). Semua senjata milik pasukan Dena dilucuti dan diserahkan pada Belanda, c). Jika perintah ini tidak diindahkan atau dilaksanakan dalam waktu satu kali dua puluh empat jam, maka semua isi kampung Dena akan dibakar habis dan pasukan Dena akan ditahan dan disere ke dalam penjara. Sebelum pacahnya perang Dena para ulama dan Tokoh Masyarakat sudah malakukan persiapan yang matang berpusat di Mesjid Raya Dena, dimana H. Usman, H. Abdurrahman, H. Abdul Azis bersama ulama lain mengobarkan semangat jihad perang sabil (Lewa Sabil) kepada seluruh lapisan Masyarakat. Ajakan dan seruan para ulama disambut positif oleh Masyarakat. Mereka siap untuk malakukan perang sabil melawan orang kafir. Tokoh Masyarakat yang melakukan perang sabil seperti Gelarang Dena La Kao Ama Huse, La Hamu Ama Beda dll.

\section{Dampak Positif Perang Dena Terhadap Kehidupan Masyarakat Dena pada Tahun 1908-1910.}

Berawal dari ketidak puasaan terhadap perlakuan bangsa penjajah yaitu bangsa Belanda, dimana peristiwa pemberontakan yang dilakukan oleh bangsa Belanda mengakibatkan masyarakat Dena banyak yang harus menderita terutama dengan diberlakukannya sistem kerja rodi dan sistem pemungutan bea pajak. Hal ini merupakan penderitaan dan kematian dan membawa dampak negatif yang luar biasa terhadap kehidupan rakyat dimana rakyat banyak diperas baik tenaga maupun harta benda mereka. Adapun dampak negatif Perang Dena bagi Masyarakat Dena antara lain : 
a. Mengakibatkan kerugian yang tidak sedikit dari masyarakat dena.

b. Jiwa rakyat menjadi tertekan ditambah lagi bahan makanan dan pakaian yang sulit didapatkan karena sebagian besar hasil pertanian harus diserahkan kepada bangsa Belanda dan tidak sedikit rakyat yang menjadi kaki tangan bangsa Belanda.

c. peperangan masyarakat dena mengalami kerugian besar baik moril, meterial dan mengakibatkan korban jiwa yang tidak sedikit. Lebih parah lagi pada tahun itu masyarakat mengalami peceklik karena pertanian tidak berhasil.

Dari sinilah bangkit rasa nasionalisme dam semangat menjujung tinggi perjuangan rakyat Dena untuk melakukan perlawanan terhadap bangsa Belanda agar tidak dijajah oleh bangsa lain. Adapun dampak positif antara lain:

a. Membuat masyarakat lebih maju dan mendapat motivasi agar Desa Dena lebih tidak dijajah lagi oleh bangsa lain ataupun negara-negara penjajahan seperti yang dilakukan oleh Belanda pada tahun 1908-1910.

b. Masyarakat Dena lebih maju dari sesudah dijajah oleh bangsa Belanda,

c. Adanya Perang Dena tersebut membuat masyarakat Desa Dena lebih bangkit dari tidak ada penghasilan pertaniaan akibat dirampas oleh penjajahan Belanda pada tahun 1908-1910, sehingga masyarakat itu sendiri bisa mendapatkan penghasilan pertanian mereka lagi dengan cara melakukan kerja keras dari tidak menjadi ada.

d. Masyarakat Desa Dena sekarang udah kaya dengan penghasilan pertanian setelah dijajah oleh bangsa Belanda.

\section{SIMPULAN DAN SARAN}

\section{Simpulan}

a) Latar belakang terjadinya perang Dena tahun 1908-1910, merupakan salah satu pertempuran besar yang pernah dialami oleh masyarakat Dena dalam menghadapi penjajahan Belanda. Peperangan ini melibatkan seluruh wilayah Bima khususnya masyarakat Dena, Karena masyarakat Dena tidak ingin wilayahnya dijajah atau dikuasai oleh Belanda atau orang-orang kafir, maka masyarakat Dena mempertahankan wilayahnya agar tidak dijajah atau dikuasai oleh daerah lain

b) Proses terjadinya Perang Dena tahun 1908-1910, Manyarakat Dena merupakan salah satu daerah yang menentang kolonial Belanda karena telah melihat berbagai penindasan yang mereka lakukan kepada rakyat. Perjuangan masyarakat Dena dibantu oleh $H$. Usman yang juga menjadi pemimpin spiritual pemberontakan. Dalam perang Dena ini telah berjatuhan korban yang tidak sedikit baik korban harta maupun jiwa, Perang Dena berlangsung selama dua tahun yaitu antara tahun 1908-1910.

c) Masyarakat Dena mengalami kerugian besar baik moril, meterial dan mengakibatkan korban jiwa yang tidak sedikit. Lebih parah lagi pada tahun itu masyarakat mengalami peceklik karena pertanian tidak berhasil.

\section{Saran}

a) Disarankan kepada masyarakat Desa Dena Kecamatan Madapangga Kabupaten Bima, bahwa hasil penelitian ini dapat dimanfaatkan sebagai bahan acuan dalam mengetahui sejarah latar belakang dan dampaknya Perang Dena terhadap kehidupan masyarakat Dena Kkacamatan Matapangga Kabupaten bima.

b) Disarankan kepada instansi pemerintahan supaya dapat menyimpan berbagai macam bukti sejarah dan tidak memusnahkannya, agar menggali lagi dan melestarikan hal-hal yang memiliki nilai sejarah, yang diharapkan dapat membantu penulisan lainnya tentang latar belakang dan dampaknya Perang Dena terhadap kehidupan masyarakat Dena Kkacamatan Matapangga Kabupaten bima.

c) Disarankan kepada para peneliti yang tertarik untuk melakukan penelitian lanjutan, semoga hasil penelitian ini dapat bermanfaat sebagai bahan acuan dalam melakukan penelitian 
lanjutan yang lebih luas, berusaha mengungkap hal-hal yang belum bisa diungkap dalam penelitian ini.

\section{DAFTAR RUJUKAN}

Abdullah Tajib, H. BA.1995. Sejarah Bima Dana Mbojo. PT. Harapan Masa PGRI Jakarta.

Achmadi CholidNarbuko, Abu.2009. “Metodologi Penelitian" Jakarta.

A. Dwi, Editor Joebagio Hermanu; Humardani Ilustrator Haryana.,,Indonesia-Sejarah-Studi Dan Pengajaran",Jakarta, 2009.

Ahmad Amin, “Sejarah Bima”, Kantor kebudayaan Bima, 197

AlanMalingi, "Mengunjungi Obyek-Obyek Wisata di Daerah Bima", Bima, 2010. A.M Badriyatim, "Sejarah Peradaban Islam", Jakarta, 2008

Aman, 2011. Model Evaluasi Pembebelajaran Sejarah. Yogyakarta. Penerbit Ombak

Arikunto, Suharsimi. 2006. "Prosedur Penelitian Suatu Pendekatan

Teoritik”Jakarta: Rineka Cipta.

B. Matthew Milles, Michael Huberman. 1992.“Analisis Data Kualitatif'. Jakarta: UI Press.

Depdikbud, 1976. Ensiklopedia Nasional Indonesia. Jakarta. Depdikbud, 1997. Ensiklopedia Nasional Indonesia. Jakarta.

Djakariah H. Ahmad,1991. "Sekilas Perang Dena”

Djoened M, 2008. Poesponegoro, "SejarahNasional Indonesia I" - cet. 2-edisi pemuktahiran, Jakarta: Balai Pustaka.

Faisal, Sanapiah,1990. Penelitian Kualitatif, "Dasar dan Aplikasi", YA3 Malang. Gottchalk Louis, 1986. Mengerti Sejarah, UI Pres, Jakarta.

Helius, Sjamsudin, 2007, Metodelogi Sejarah, Yogyakarta: Ombak.

IKIP Bima, 1978."Pergerakan Melawan Penjajahan Belanda", Bima.

Ismail Hilir,2004."Peran Kesultanan Bima Dalam Perjalanan Sejarah Nusantara", Bima.

Ismail Hilir, "Sejarah Mbojo Bima (Dari Jaman Naka Ke Jaman Kesultanan)"

Kuntowijoyo, 1995. Pengantar Ilmu Sejarah. Jakarta Bentang.

Latief Abdul Juraid, 2001. Manusia Dan Sejarah. Hasanuddin Unifersity, Ujung Pandang.

Listiyani D. A,2009.Editor Joebagio Hermanu; Humardani Ilustrator Haryana.,Indonesia-Sejarah-Studi dan Pengajaran",Jakarta.

Loir H. C/Salahudin S. M. R,2009."Bo" Sangajikai Catatan Kerajaan Bima",- cet. 1.-Jakarta yayasan obor Indonesia.
Maleong,J., (2004) “Metode Penelitian Kualitatif".Bandung: Remaja Rosdakarya.

Malingi Alan, 2010. “RagamPakaianAdatBimaDompu”, Mataram.

Marwati Djoened M, 2008. "Sejarah Nasional Indonesia III"- cet. 2-edisi pemuktahiran, Jakarta: BalaiPustaka,

Margono, 2004."Metodologi Penelitian Pendidikan", Jakarta.

M.Ag Mukhlis, 2011. "Permata Kearifan Dari Naska Kuno Kesultanan Bima" Mataram.

M. Purwati, 2010.“Pesona Wisata Nusa Tenggara Barat”, Klaten.

M,S. Bambang D.L, \& Riana Dra. Rati, 2005.“Teknik penulisan Karya Ilmiah", Semarang.

Rahman, Fachrir,2011: Islamdi Bima kajian Historis Islamisasi Era Kesultanan", PT.Alam Tara Learning Institut Mataram.

Satori, Djam"an,2011: “Metodelogi Penelitian Kualitatif”,Alfabeta, CV Bandung. Sugiyono. 2010. "Metodolgi Penelitian Kualitatif", Bandung: Penerbit Alfabeta.

Tauafan,I.Naniek, 2010: “Demi Masa Kenangan perjalanan Karir", Musium kebudayaan samparaja Bima NTBIndonesia

Tajib A. BA, 1991. "Sejarah Bima-Dana Mbojo Maja Labo Dahu”, Bima. 